\title{
Depoimento
}

Paulo Sérglo Pinheiro*

\section{Eric Hobsbawm: um espelho do mundo em mutação}

Eric Hobsbawm, o mais eminente historiador de língua inglesa, está em São Paulo. Participou do Congresso sobre Cidadãos e Escravos no Mundo Moderno, na UNICAMP, em Campinas, onde fez conferências na tarde do dia 6 e na manhā do dia 7. Se houvesse um Prêmio Nobel para a História, há muito tempo o antigo professor da Universidade de Londres ja teria sido premiado. Hobsbawm, 71 anos - "sou de 1917, como a revolução soviética..." sublinhou na conversa -, $€$ o grande renovador da História Social.

Seus numerosos livros e ensaios, largamente traduzidos, influenciam geraçóes de historiadores, do Japão, passando pelos Estados Unidos (onde nos últimos cinco anos esteve em períodos regulares na New School for Social Research, em Nova York) ate o Brasil. Um de seus muitos méritos foi conceber a história do trabalho industrial como a história de toda a sociedade. Sem excluir categorias pouco estudadas, como em seus livros Bandidos e Rebeldes Primitivos, que iluminaram as pesquisas sobre a violência e o protesto. Sua trilogia sobre a história contemporânea, que atingiu o grande público, tornando-se best seller em toda a parte, A Era das Revoluçóes, A Era do Capital e A Era dos Impérios (que, como os dois anteriores, já aqui traduzidos, sera publicado em agosto pela editora Paz e Terra), alia uma formidável erudição com o prazer do texto. A última coleção de seus ensaios publicada em português, Mundos do Trabalho, abrange a iconografia do movimento socialista na Europa até um alentado estudo sobre os sapateiros, bastiōes das revoluções do século XIX, incorporando informaçōes da Bulgária até o Paraná. Essa capacidade de Hobsbawm, graças a sua incansável curiosidade sobre as transformaçōes na sociedade "desde a Idade da Pedra até o laser", de fazer associaçōes complexas entre épocas e países diferenciados, abrange a América Latina. Sucessivas viagens à Colômbia, Chile e Peru têm suscitado provocantes ensaios sobre a conjuntura política desses parses, publicados geralmente na influente The New York Review of Books, da qual Hobsbawm é um colaborador freqüente.

* Entrevista transcrita do jornal $O$ Estado de S. Paulo, de 12 de junho de 1988. Caderno 2. 
Como se não bastasse toda essa variedade de interesses, $\varepsilon$ ainda um respeitado especialista do jazz, tendo publicado livro e ensaios sob o pseudônimo de Francis Newton. Para conversar sobre a perestroika, a crise dos partidos socialistas, as revoluções estudantis de 1968 e, inevitavelmente, sobre a transição brasileira, Hobsbawm recebeu durante uma manhã o Caderno 2, para uma entrevista exclusiva para $O$ Estado de $S$. Paulo cujos principais trechos aqui publicamos:

Caderno 2: Aqui no Brasil estamos sempre procurando fazer uma avaliação mais elaborada sobre a chamada perestroika e o processo de abertura na Uniâo Soviética. Como o senhor avaliaria os últimos desenvolvimentos desse processo?

Eric Hobsbawm: Não sou especialista em assuntos soviéticos e, portanto, o que tenho a dizer nāo é particularmente qualificado.

Gostaria de lembrar, primeiro, que por aproximadamente trinta anos houve toda uma escola de ciência política, nos Estados Unidos e no Ocidente, que afirmava ser inteiramente impossível algo como Gorbachev acontecer na URSS. Entretanto, o surgimento de Gorbachev, da glasnost e da perestroika refuta toda a teoria do totalitarismo. Aparentemente as diversas teorias definiram os países como totalitários precisamente pela sua incapacidade de caminharem na direção em que a. União Soviética, evidentemente, está indo. Em segundo lugar, parece-me que o próprio Gorbachev declarou claramente qual é a justificativa tanto para a glasnost como para a perestroika. Essencialmente, é a crise da economia da União Soviética; a estagnação crescente dessa economia; o crescente atraso da União Soviética em relação a outros países, e, portanto, a necessidade básica de modificar o sistema de administração burocrática e o planejamento central. A novidade, creio, sobre Gorbachev e a perestroika, é que ele liga este processo a uma necessidade de democratizaçāo política. Em outras palavras, não é uma mera mudança tecnocrática, destinada a promover elementos mais ou menos democráticos. Para mim, essas parecem ser as características de mudanças análogas, na China. Mas no que diz respeito a Gorbachev, ele aparentemente acredita ser impossível realizar essa re- forma sem uma democratização. Uma democratização não necessariamente no sentido em que nós, do Ocidente, entendemos: com eleições com escotha entre partidos diferentes, por exemplo. Acho que essas são as características principais.

As dificuldades são enormes e de dois tipos: em parte, há a participação dos interesses constituídos da burocracia, incluindo a burocracia do Partido Comunista e, em parte, a dificuldade em proporcionar incentivos econômicos efetivos e melhorias para a população trabalhadora. A União Soviética operou durante muito tempo uma economia ineficiente, mas relativamente estável e poderia continuar assim se nâo fosse a competiçâo internacional. Mas, essencialmente, a URSS é uma economia que oferece aos trabalhadores comuns uma grande insegurança e liberdade num nível econômico muito baixo. Isso vai ser trocado pela esperança de uma considerável melhoria no padrão de vida e na possibilidade de escolha. Mas, no momento, não há muita escolha e melhorias no padrão de vida soviético e, consequientemente os trabalhadores - que devem ser essencialmente a base do sucesso da perestroika - estão esperando para ver o que vai acontecer a eles.

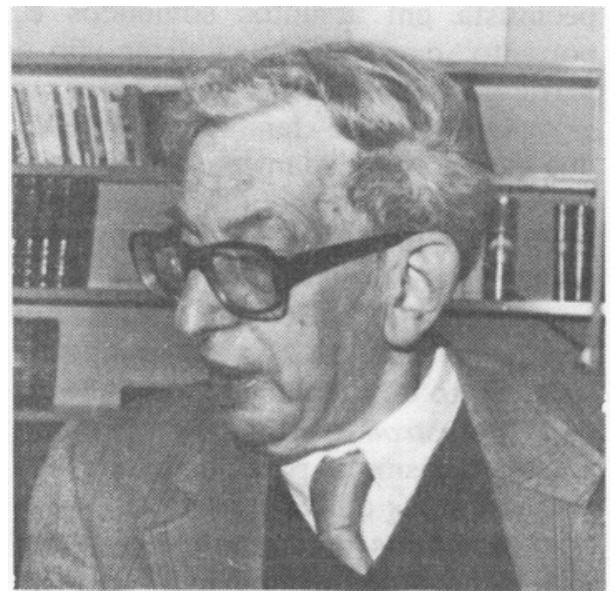


Caderno 2: Poderlamos dizer que o processo ocorreu porque as condiçốes estavam maduras. Mas... por que somente agora? Como o senhor explicaria a emergência deste processo? Que foi a faisca?

Hobsbawm: Creio que năo posso responder a essa pergunta em detalhe $e$ acho que ninguem pode. A questão principal é como um homem, com as opiniōes de Gorbachev, conseguiu chegar à mais alta posição da Uniẫo Soviética. Isto sugere que dentro do proprio Partido Comunista deve ter havido um apoio considerável para esse tipo de movimento reformista. Todavia, acho que podemos generalizar deste modo: primeiro, no curso de transformar a União Soviética num Estado moderno, numa sociedade moderna, numa economia moderna, gerou-se o que no Ocidente chamamos de classe média: um grande setor culto e tecnicamente competente em alto grau. E foi certamente entre eles, descontentes com uma administração tradicional, militarista e em geral muito ignorante, que isso se tornou intenso. Parece-me que não é por acaso que os centros acadêmicos, como o de Novosibirsk, foram e permanecem, o cérebro da perestroika. Em segundo lugar, mais especificamente, acho que um grande número de controladores da economia - equivalente aos industriais daqui - os grandes diretores de fábricas, usinas, e assim por diante, devem perceber, cada vez mais, a ineficiência e a natureza cática da economia que eles deveriam controlar. Devem ter entendido que perderam muito tempo nâo aumentando realmente a produção e, sim, cumprindo um planejamento que significava por exemplo estocar pilhas de matéria-prima ou fazer negócios privados com outras companhias. Isso é uma forma extremamente ineficiente de gerir a economia. Entăo, acho que houve um apoio enorme por parte desses setores cultos, que representam agora um grande setor da população soviética, se comparado com qualquer Época passada. A oposição principal vem da burocracia e, passivamente, da massa de trabalhadores. Por que somente agora? Pareceme que, de alguma forma, os vinte anos de Brezhnev foram, inicialmente, uma espécie de ar puro, depois das tragédias de Stalin, pós-Stalin 6 Kruschev. Por bastante tempo, este ar puro foi bem aceito por todos e houve, na verdade, uma melhoria modesta - mas muito específica - nas condições materiais. Eventualmente, os custos da estagnação de Brezhnev foram tais e isso inclui, por exemplo, o crescimento espetacular da corrupção no sistema - que eles se tornaram intoleráveis dentro do Partido; talvez, mais ainda, dentro dos setores militares e da polícia. Andropov foi o primeiro dos grandes reformadores. Ele era o chefe da KGB.

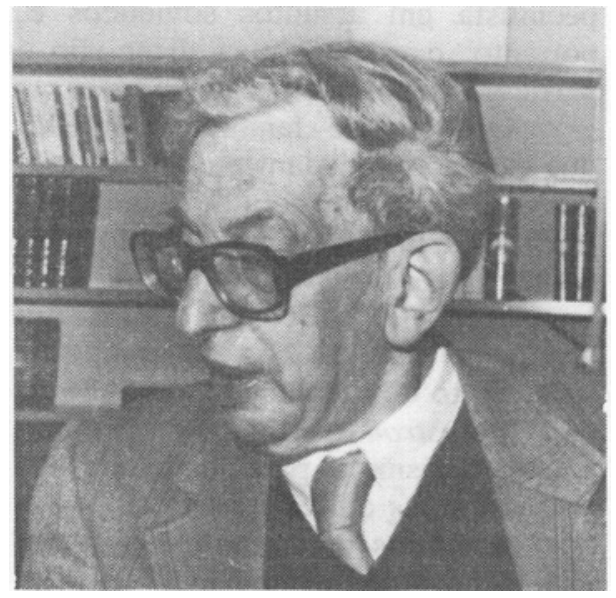

Caderno 2: Um aspecto importante da perestroika é a reabilitaçāo de muitas figuras polfticas na União Soviética. Por que tem sido tão dificil reabilitar Trotsky... se este $e$ um caso de reabilitaçāo?

Hobsbawm: Aqui, novamente, não tenho nenhuma informação em particular mas, como você sabe, reabilitar figuras do passado ou personagens da história da Revolução Russa $e$ uma questão altamente política na URSS; poderíamos dizer que é uma questão ideológica, que não pode ser julgada nos padróes da história acadêmica. De certa forma, a reabilitação de Trotsky seria algo como reabilitar Martinho Lutero, na Igreja Católica. Por um lado, é mais fácil porque Trotsky nunca encontrou uma Igreja vazia como Lutero mas, por outro, é muito difícil porque durante duas ou três geraçōes de comunistas e, particularmente, os soviéticos, definiram
"Parece-me que figuras do passado não são, necessariamente, boas para o futuro" 
sua ortodoxia como não sendo a de Trotsky. Earticularmente claro, para você e para mim, que esses velhos conflitos atualmente têm apenas importância histórica. Todavia, o problema não é acharmos que se deva reabilitar Trotsky, mas, sim, uma Igreja reabilitar seus grandes hereges. $E$ acho que isso demora muito mais.

Caderno 2: Se tentarmos entender o que está acontecendo na Europa, o que o senhor diria sobre a alegada crise dos partidos comunistas dos paises europeus?

Hobsbawm: Não há uma ligação lógica entre a perestroika e a crise. Diria que é uma crise da esquerda e não uma crise dos partidos comunistas, porque $t$ uma crise que afeta todos os movimentos trabalhistas e socialistas. Acredito que o desenvolvimento da União Soviética tem sido uma fonte de inspiraçāo para as pessoas de esquerda, não apenas comunistas, simplesmente porque todo socialista tem que carregar o pesado fardo de tentar explicar a União Soviética, mesmo que ele não seja favorável ao stalinismo soviético. As pessoas nāo dizem que um sistema stalinista a consequiência lógica do socialismo? Conseqüientemente, $\ell$ um enorme alívio para a esquerda descobrir que este é um sistema capaz e disposto a reformar-se. Talvez seja melhor dizer que a crise da esquerda mais sutil nos partidos comunistas do que entre os partidos democráticos; porque os partidos socialistas se ajustaram há muito tempo, de modo a ser partidos de governo em potencial e, portanto, partidos de economia mista, reformistas; ao passo que os partidos comunistas, pela propria origem, sempre estiveram limitados a uma atitude de oposição, ou de transformação imediata ou, pelo menos, à esperança de transformação imediata. $O$ exemplo da tal crise $\epsilon$, logicamente, o Partido Comunista Francês que, virtualmente, desmoronou em dez anos. De modo geral, até mesmo o Partido Comunista Italiano está, no momento, recuado e, de certa forma, com medo de perder terreno para o Partido Socialista. As pessoas costumam falar sobre o euro- comunismo, mas, na verdade, o fenómeno mais interessante é o socialismo europeu: o renascimento dos partidos socialistas desde os anos 60 , numa base nova, freqüentemente numa base muito mais moderna politicamente. Isso é obvio na França, onde os partidos socialistas foram virtualmente destruídos e o Partido Socialista, de Mitterrand, teve uma construção nova, baseada no que sobrou. E, na Espanha onde o Partido Socialista virtualmente deixou de existir durante e depois da Guerra Civil -, o novo partido de Gonzalez simplesmente reclamou o título, mas não num esquema de continuidade. Também na Itália, em Portugal, na Grécia e assim por diante. Todavia, acho que há partidos socialistas tradicionais que, por serem partidos democráticos reformistas há muito tempo se adaptam mais facilmente. Este $\epsilon$ claramente 0 caso da Alemanha, da Suecia e de outros parses como a Áustria. E há lugares em que eles não foram capazes de se adaptar, como na Grã-Bretanha, onde mergulharam numa crise da qual s6 agora estão emergindo. Mas essa uma crise à parte. Acho que, essencialmente, $\epsilon$ uma conseqüência das mudanças na estrutura da economia mundial e das sociedades, desde 1950. Essas mudanças liquidaram as bases sociais tradicionais dos movimentos trabalhistas $e$, incidentemente, desde o começo dos anos 70 também dizimaram a política reformista tradicional do Estado; política essa que a maioria dos governos democratas do Ocidente (sociais-democratas ou não) tem adotado durante gerações.

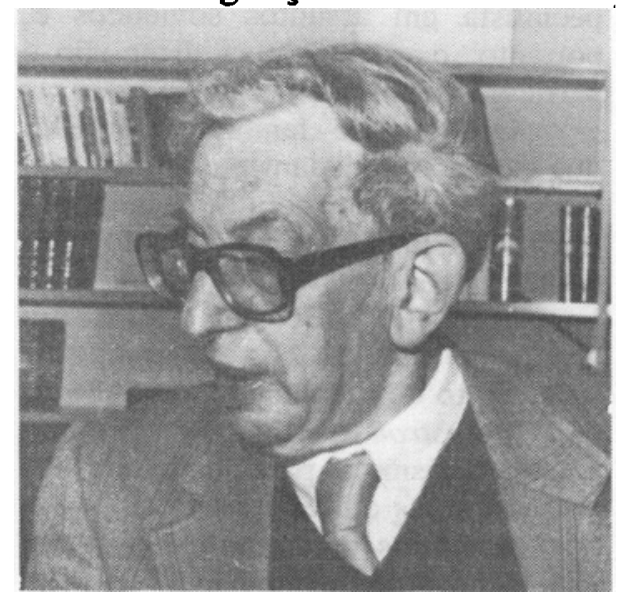




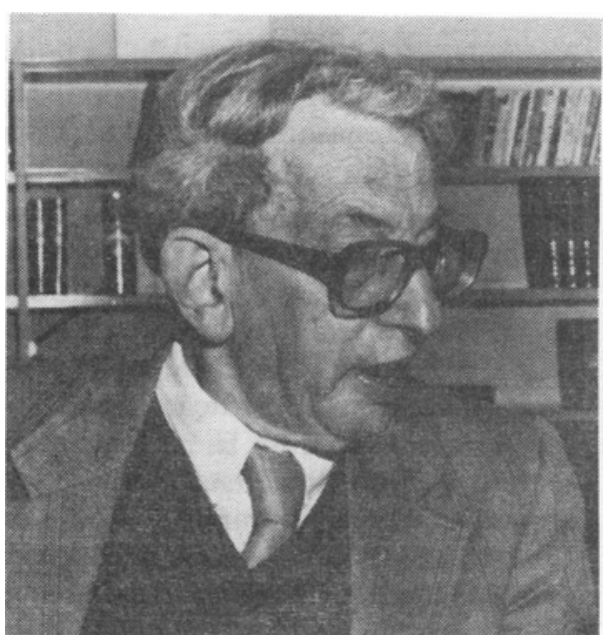

Caderno 2: $O$ senhor publicou um estudo sobre a classe trabalhadora, chamado A Marcha da Classe Trabalhadora Parou? Por que essa interrogação no final? $O$ senhor tem alguma dinvida sobre isso? $O$ que quis dizer com essa interrogaçäo?

Hobsbawm: A interrogação não $\epsilon$ minha. Essa interrogação pretendia significar que 0 estudo representava uma discussão sobre a esquerda. Há dez anos dei uma conferência na Inglaterra, na qual tentei avaliar a situação da classe trabalhadora no país, cem anos depois de Karl Marx. Cheguei à conclusão de que o desenvolvimento da classe trabalhadora, assim como uma boa parte do povo ingles que é composto principalmente de trabalhadores - havia parado no começo dos anos $50 \mathrm{e}$, desde então, notamos um declínio gradual. O clima no movimento trabalhista britânico era tal, que minha palestra provocou uma discussão violenta: especificamente por parte de alguns setores do movimento sindical que se ressentiram com minha crítica à tática nos anos 70 (dividir a classe trabalhadora, em vez de criar uma união). E o estudo a que você se referiu - publicado no começo dos anos 80 - foi essencialmente um relatório dessa discussão. Mas, é claro, o declínio - relativo ou absoluto - do apoio à classe trabalhadora não é mais a questão. A questáo, agora, é como pode haver uma recuperação. Do meu ponto de vista, acho que.não devemos ser muito pessimistas sobre as possibilidades dos partidos e movimentos socialistas na Europa porque o fato é que esses partidos, praticamente em todos os lugares da Europa, com exceção da Turquia e da Irlanda, constituem os governos, ou a maioria dos governos alternativos. Assim, não estamos falando de partidos ou movimentos que desapareceram de cena. Alguns de fato desapareceram, como - Partido Comunista Francês; mas os partidos socialistas, na forma socialista ou comunista, constituem fatores principais para os governos. Portanto, a questão não é se esses partidos têm futuro, mas que tipo de futuro.

Caderno 2: $O$ senhor aplica esse mesmo tipo de reflexão ao marxismo? Nos anos 70 , discutimos muito a crise do marxismo no Brasil e na América Latina. Qual é a situação, agora?

Hobsbawm: Existe, indubitavelmente, uma crise do marxismo que reflete a crise da esquerda, em geral. Há muitas razões para essa crise que, essencialmente, estamos vivendo desde $o$ início dos anos 70, e talvez antes, num período de crise global da economia, seja a capitalista, seja, também, a socialista. Como já mencionei, antes a esquerda teve, no passado, duas alternativas ou possibilidades de programas complementares para essa situaçăo, elaborados durante a ultima crise geral, nos anos 30 . Uma era o planejamento central, e a outra era uma administração da economia. Agora, nos anos 70 e 80, ambos se mostram suscetíveis de críticas. $O$ planejamento central stalinista e a saída pela economia - que também foi criticado - sucumbiram temporariamente com o fim do longo boom de trinta anos, o que, na verdade, os encorajou. E, conseqüentemente, a esquerda nāo encontrou uma resposta para a crise. Por outro lado, podemos dizer que ninguem mais tem essa resposta. Por exemplo, aqui no Brasil, tentaram muitas formas de lidar com a crise e nenhuma delas adiantou. Ainda assim, para os marxistas ou para os socialistas, essa falha, na anallise da superação, $\epsilon$ intelectualmente mais séria do que para os capitalistas. Entâo, há um outro aspecto de crise do 
marxismo - e acho que ele é um reflexo da situação de 1968, no sentido em que o renascimento do marxismo foi uma conseqüência da radicalização do final dos anos 60 , um fenômeno mundial indiferente às condições políticas. Baseado no movimento estudantil lembramos que os anos 50 e 60 representaram um aumento sem precedência e esmagador no número de pessoas que faziam cursos superiores; assim, os estudantes eram, demograficamente, uma parte significativa da população, o que não acontecia antes. Em 1848, nos movimentos estudantis do século XIX, os estudantes eram 5 mil pessoas nas cidades grandes. Enquanto, por volta de 1968, estamos falando em termos de centenas de milhares. Agora, acho que essa radicalização levou um grande número de pessoas para o marxismo. Ao mesmo tempo, a realidade na qual as pessoas viviam nos anos 60 e 70 estava tão distante da realidade que Marx descreveu em 1867 - ou Lênin nos anos 20 - que, na verdade, o marxismo clássico era menos atraente e, conseqüentemente, encontramos todos os tipos de novos marxismos. O marxismo foi, em grande escala, parece-me, uma forma de infundir um caráter político radical, ou mesmo revolucionário, no que quer que fosse a ideologia da moda. Encontramos, então, um grande número de marxismos refinados: o marxismo estruturalista, o marxismo psicoanalítico, o marxismo econômico neoclássico, e assim por diante. Acho que, para muitas dessas pessoas, o marxismo indicava que "somos lacanianos, estruturalistas, mas somos também revolucionários" e, parece-me, isso foi uma base relativamente insatisfatória e instável sobre a qual se reviveu o marxismo como análise do mundo $\mathrm{e}$, conseqüentemente, facilmente esgotável. Em parte, devido a uma mudança política das geraçōes de estudantes, a maioria na França, movendo-se bruscamente para diferentes direções em poucos anos e, também, de certa forma, por causa das ideologias às quais o marxismo esteve ligado em 1968. E finalmente, é claro, - marxismo sempre refletiu o estado da radicalização política dos movimentos para mudar o mundo e, à me- dida que estes movimentos estão em crise, o marxismo também está em crise. Em alguns países, parece-me, essa crise é muito mais aguda por razóes políticas - ou por razões de moda, como na França - mas ela existe claramente em muitos países, e não podemos negar que está também ligada à crise dos partidos comunistas.

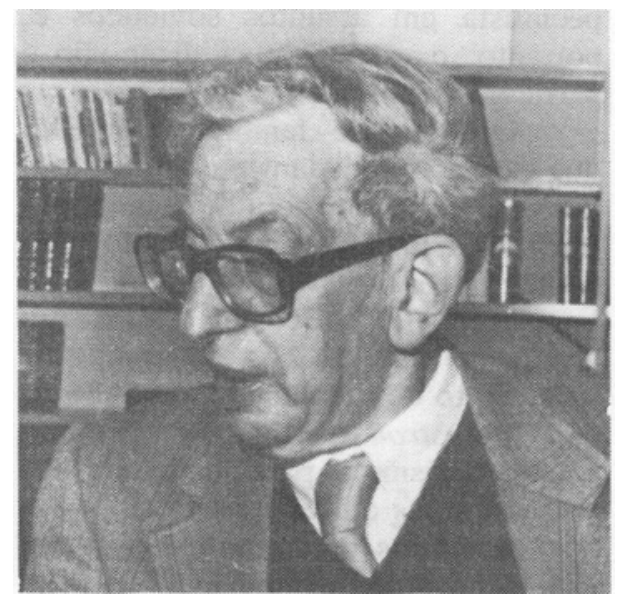

Caderno 2: Apesar de toda essa crise, a historia das classes trabalhadoras experimentou enorme desenvolvimento nos últimos dez anos. Mesmo no Brasil, paradoxalmente, apesar da ditadura $e$ do regime autoritário, muitas pesquisas e novos livros apareceram; $e$ o senhor sabe também que seus livros são muito lidos aqui. Como o senhor explica esse sucesso $e$ riqueza das pesquisas em termos de orientação e descobertas sobre a história da classe trabalhadora - da história social em geral?

Hobsbawm: É claro que há uma crise do marxismo, mas isso não quer dizer que, no curso geral do desenvolvimento do trabalho marxista e da análise marxista, houve recessão. De certa forma, o que desapareceu foi uma enorme quantidade de literatura sobre aquilo que se dizia marxista. $\mathrm{E}$, assim, foi feito um considerável número de modificaçōes importantes por exemplo, algumas das séries econômicas básicas de Marx - e pareceme que há importantes trabalhos progredindo. Como você mesmo observa, muitas obras marxistas continuam a ser publicadas. Nos Estados Unidos, 
por exemplo, havia um grande número de estudantes radicais no final dos anos $60 \mathrm{e}$, apesar do fato de muitos deles terem deixado de ser radicais, hoje há, provavelmente, um número muito maior de historiadores marxistas ou acadêmicos marxistas naquele país, do que havia antes. $\mathrm{Na}$ verdade, não estamos falando sobre uma crise, mas da crise comparada com a situação de vinte ou cinqüenta anos atrás. Sobre a questão específica que você mencionou - a situação do marxismo na Inglaterra - não creio que possa explicar o que a energia intelectual do meu país, voltada para a teoria marxista, contribuiu para a História. Uma razão talvez seja a ausência de uma forte tradição de educação filosófica, assim como existiu na Alemanha e, de uma forma diferente, na França. Outra, talvez seja o fato de que na Grã-Bretanha - pelo menos quando eu era estudante - nas principais universidades, Oxford, Cambridge, a História era uma matéria importante; não uma matéria para especialistas, mas um estudo difundido na universidade: o mesmo que o Latim e o Grego haviam sido.

Com o declínio do Latim e o Grego, particularmente na Grã-Bretanha - onde a política e a Constituição eram fortemente enraizadas na História -, esta tornou-se uma matéria importante para a educaçāo dos jovens que, esperava-se, iriam ingressar na vida pública; assim como estudo do Direito o foi no Brasil e em muitos países da América Latina. Então, muitas pessoas estudaram História. De qualquer modo, este $€$ um fenômeno peculiar e estou muito próximo deste fenômeno para ser capaz de ver em perspectiva - já que pertenço precisamente àquela geração na qual isto foi particularmente marcante. Eu diria também que, naquela época, nāo era só a História que atraía os marxistas e o marxismo. Nos anos 30, havia também, paradoxalmente, a Ciência Natural, e um grupo bastante representativo de cientistas britânicos tornou-se marxista naquela Época. Matemáticos, etc.

Hoje o marxismo virtualmente desapareceu do meio da Ciência Natural, e isso desde os anos 40. Em parte, como resultado do desenvolvimento da União Soviética, mas não totalmente. Considerando que isto permaneceu na Historia, eu, como historiador, diria que a História se liga particularmente bem à interpretação marxista, desde que, no meu ponto de vista, o conceito materialista é o centro e o âmago da análise marxista.

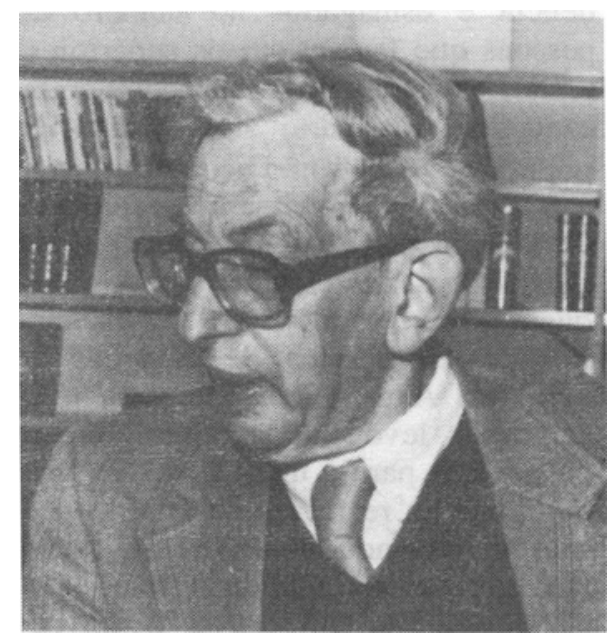

Caderno 2: De certa forma, essa influência foi tâo grande que, de fato, "construiu??" a História Social, que é hegemônica na maioria das universidades. $O$ senhor concorda com esse ponto de vista, ou seja, a disciplina não é mais vista como História Marxista, mas como História Social, que é dominante na maioria dos departamentos de História, mesmo nos Estados Unidos?

Hobsbawm: Gostaria que você estivesse certo e gostaria que toda a Historia Social fosse uma História Marxista, mas sinto dizer que não é o caso. Acho que os marxistas tiveram um papel importante ao focalizar e cristalizar a História Social. Entretanto, acho que as raízes da moderna História Social não são particularmente marxistas.

Caderno 2: Como toda essa historia sobre os odores, os perfumes, as mentalidades, de alguns livros franceses?

Hobsbawm: Parece-me que esse é o tipo de História Social que não é necessariamente marxista. Acho que a história marxista - na verdade qual-
"Qualquer hist6ria hoa não é apenas uma tentativa de investigar e analisar o passado, mas analisar como o mundo muda. $O$ problema hásico é đescobrir como a humanidade começou na Idade da Pedra e chegou à Idade Nuclear" 
quer história boa - não é apenas uma tentativa de investigar, descrever e analisar o passado, mas analisar como o mundo muda. O problema básico da história marxista, ou de qualquer história, é descobrir como a humanidade começou na Idade da Pedra e chegou à Idade da Tecnologia, a Idade Nuclear. E, conseqüentemente, o problema principal da analise histórica, que até mesmo o historiador mais especializado não pode esquecer, é como explicar essa extraordinária transformação. Entretanto, há outro aspecto que me interessa muito que $\epsilon$ usando terminologia marxista clássica - o problema da relação entre a base e estrutura, ou seja, como as várias atitudes ou atividades da vida estāo ligadas, num período particular. Agora, o tipo de História Social que analisa seja lá o que for, a história do cheiro, ou da menstruação ou alguma coisa assim, não tem ligação direta, em si mesma, com os problemas principais da transformação histórica. Por outro lado, tem uma relação direta com o problema das superestruturas, exatamente como, digamos, o conceito de sexualidade se relaciona com outros aspectos da sociedade. São, freqüentemente, muito inteligentes, intuitivas e perceptivas, mas não acho que sejam marxistas.

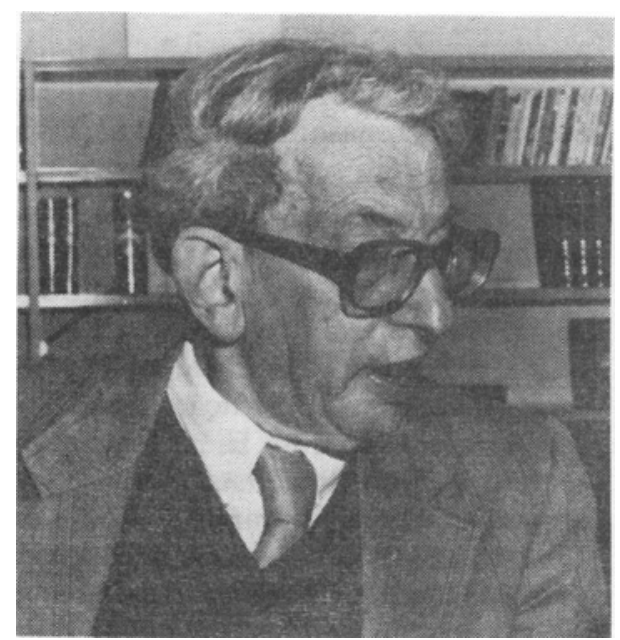

Caderno 2: Posso convida-lo a fazer algumas consideraçöes sobre 0 atual desenvolvimento da situação so- cial e polftica do Brasil depois do fim do regime militar?

Hobsbawm: Você pode convidar, mas não acho que possa responder, simplesmente porque não tenho conhecimento suficiente sobre a situação do Brasil. Acho que o País, no momento, está vivendo um clima especial. Visito o Brasil, ocasionalmente, há muito tempo, e não me lembro de um clima semelhante, no qual o povo não tem certeza quanto ao futuro, mostra-se pessimista, não sabe ou duvida se vão ser encontradas soluções. Acho que isto é novo. Os brasileiros, mesmo no passado, sempre foram muito esperançosos quanto ao futuro, de uma forma ou de outra. Mas não acho que este seja um problema específico do Brasil. Eu diria que a América Latina tem sido a principal vítima da crise atual. Tanto economicamente, como no sentido de uma certa desagregação política. Têm havido mudanças; porém mudanças que parecem não ser ainda soluções alternativas. Então, se você olha não apenas para o Brasil, mas para toda a América Latina - para o México, para a Argentina, para o Peru, para a Colômbia - você encontra uma situação de drama, de crise e de incertezas sobre o que acontecera a todos esses países. No Brasil, isto pode ser mais dramático por causa do contraste com um período recente de expansão autoconfiante e esperança. Mas isso não é um fenômeno especificamente brasileiro. Acho que ele deve ser visto numa perspectiva global. Nessa situação política, tudo o que posso dizer $\epsilon$ que a transição parece estar se prolongando por um tempo muito longo e, talvez, também possa dizer que não me parece um bom sinal para a política do País que pelo menos duas das figuras no comando das próximas eleiçóes presidenciais tenham sido pessoas ou fenómenos de quem eu ouvi falar há 26 anos, quando vim ao Brasil pela primeira vez. Parece-me que figuras do passado não sâo necessariamente boas para o futuro.

Paulo Sérgio Pinheiro é professor de Ciência Política da Universidade de São Paulo. 